\title{
Aceitunas tipo negras. Estudio comparativo de tres procedimientos para la conservación previa de frutos de la variedad gordal ( $O$. europaea regalis).
}

\author{
Por M. C. Durán Quintana, M. Brenes Balbuena, P. Garcla García, \\ M. J. Fernández González y A. Garrido Fernández.
}

\author{
U.E.I. de Biotecnología de Alimentos. Instituto de la Grasa y sus Derivados (C.S.I.C.)
} Avda. Padre García Tejero, 4. 41012 - SEVILLA

\section{RESUMEN}

Aceitunas tipo negras. Estudio comparativo de tres procedimientos para la conservación previa de frutos de la variedad gordal (O. europaea regalis).

El trabajo presenta los resultados físico-quimicos y microbiológicos de las salmueras de tres procedimientos de conservación previa de aceitunas de la variedad Gordal, así como sus efectos en los principales atributos de calidad del producto final: color y textura. Dos de ellos han consistido en la utilización de niveles bajos de $\mathrm{NaCl}$ y la corrección inicial del $\mathrm{pH}$ para facilitar el crecimiento de una flora láctica. El otro ha sido un medio fuertemente acidificado con acético.

En todos ellos ha tenido lugar un proceso fermentativo en el que se han desarrollado bacterias lácticas, fundamentalmente Lactobacillus plantarum y Pediococcus (que incluso han predominado en algunos casos) y levaduras, que han coexistido con las anteriores a lo largo de todo este período. La evolución de las caracteristicas físico-químicas ha sido distinta, según el tipo de proceso, pero no han tenido influencia en el producto final elaborado.

No obstante se recomienda que a nivel industrial se aplique el sistema aerobio por el probable efecto favorable del purgado del $\mathrm{CO}_{2}$ sobre el arrugado de los frutos. Consistiria en colocar las aceitunas en salmuera al $6 \%$ de $\mathrm{NaCl}$, con el $\mathrm{pH}$ corregido a 4,00 unidades (0,2-0,4\% de ácido acético), e inyectar aire por la columna a razón de 0,3 l/h.l. capacidad durante 8 horas al día. La concentración de sal debe elevarse a $8,00 \%$ una vez terminada la etapa de fermentación láctica.

PALABRAS-CLAVE: Aceituna gordal - Aceituna negra por oxidación - Conservación (efecto de).

\section{SUMMARY}

Ripe olives. Comparative study of three procedures for the previous conservation of gordal ( $O$. europaea regalis).

This paper shows the physico-chemical and microbiological results of the brines from three procedures of previous conservation of Gordal cultivar olives and its effects on the main quality attributes of the final product: colour and texture. Two of them have used low $\mathrm{NaCl}$ levels and initial $\mathrm{pH}$ correction to facilitate the growth of lactic bacteria. The other has consisted of a solution highly acidified with acetic

In all procedures, a fermentation process has been found. During it the growth of lactic bacteria, mainly Lactobacillus plantarum and Pediococcus (that has predominated in some cases) and yeats, which have coexisted with the previous mentioned microorganisms throught the whole conservation period, has been detected. The evolution of the physico-chemical characteristics has been different in the three processes, however they have not had any influence on the elaborated final product.
For industrial work, the aerobic system is recommended due to its $\mathrm{CO}_{2}$ purging action wich could have a favorable effect on shrivelling. It would consist of putting the olives in a $6 \% \mathrm{NaCl}$ brine, with the initial $\mathrm{pH}$ corrected with acetic to 4.00 units and bubling air throughout the column at a rate of $0.3 \mathrm{l} / \mathrm{h}$.l.c. during $8 \mathrm{~h} /$ day. The salt percentaje should be raised to $8 \%$ once the lactic fermentation has finished.

KEY-WORDS: Black olive by oxidation - Conservation (effect of) - Gordal olive.

\section{INTRODUCCION}

En la preparación conocida como tipo negras (por oxidación en medio alcalino) se han empleado generalmente frutos de las variedades Hojiblanca, Cacereña o Manzanilla. Sin embargo, en los últimos tiempos, hay algunos mercados que desean un producto con un tamaño superior al habitual. Para satisfacer esta demanda la industria española se ha visto en la necesidad de utilizar aceitunas de la variedad Gordal, que se caracterizan por su gran tamaño y que se habían dedicado hasta ahora sólo a la elaboración al estilo sevillano o español, careciéndose de la experiencia e información suficiente sobre el proceso óptimo de conservación previo a su ennegrecimiento.

En consecuencia, en el transcurso de dicha etapa han surgido una serie de problemas. Por un lado, se ha observado la aparición, en una proporción importante, de la alteración conocida como "alambrado" (1), encontrándose también que, en muchos casos, los frutos sufren una degradación importante de la textura. Dichas alteraciones ya se habían puesto de manifiesto en algunas ocasiones en las otras variedades anteriormente citadas, así como en la Aloreña.

Para evitarlos, en esta última se ha desarrollado un proceso de fermentación láctica dirigida, mediante inoculación de un cultivo puro de lactobacilos, en unas condiciones apropiadas para su crecimiento (2). Dicho sistema también se había mostrado eficaz para las Gordales en unos estydios previos realizados por Rodríguez de la Borbolla y colbs (3), relacionados con 
la conservación en salmuera del excedente de "morado" que aparecía en la preparación de aceitunas verdes. Para ello, era necesario que se emplearan concentraciones de $\mathrm{NaCl}$ inferiores al $8 \%(\mathrm{P} / \mathrm{V})$.

Por otra parte, para evitar la formación de "alambrado" se ha puesto a punto, tanto para aceitunas de las variedades Manzanilla (4) como Hojiblanca (5), un proceso de conservación en medio aeróbico, con inyección de aire mediante una columna de determinadas dimensiones que se introduce en los depósitos de fermentación (6). Los frutos conservados de esta forma presentan mejores características para la oxidación, dando lugar a un producto final con un color y textura superiores a los que se consiguen con el sistema tradicional (7).

Además, en la industria californiana, debido a la estricta legislación en materia de vertidos salinos, se ha recurrido al empleo de soluciones de ácidos orgánicos del tipo acético o láctico en concentraciones elevadas, $0,5-1,5 \%(P / V)$, que aseguran un período prolongado libre de alteraciones (8) (9) y que, en general, limitan considerablemente el desarrollo de microorganismos.

La aplicación de dicho procedimiento se ha ensayado en algunas variedades españolas, observándose que durante la conservación no se producen problemas de "alambrado" o ablandamiento en los frutos (4) (5) (7). No obstante, el sistema resulta inicialmente costoso $y$, en el caso de algunas de ellas, Manzanilla por ejemplo, da lugar a graves problemas de arrugado.

Por último, cabe señalar que se han investigado otras posibles alternativas a los sistemas comentados; pero, con ningún otro método se ha obtenido un producto apto para el ennegrecimiento (10) (11) (12).

El presente trabajo tiene la finalidad de estudiar comparativamente, en la Gordal, el comportamiento de los sistemas de conservación que han resultado favorables en otras variedades de aceitunas españolas, observándose la influencia de los mismos en las características del producto final. Los procedimientos ensayados han sido: anaeróbico tradicional, proceso aeróbico y conservación en medio ácido. En los dos primeros se ensaya, además, la posibilidad de realizar un fermentación láctica dirigida mediante la inoculación de un cultivo puro de Lactobacillus plantarum.

\section{PARTE EXPERIMENTAL}

Los frutos empleados en todas las experiencias han sido de la variedad Gordal, recolectados en el envero.

Para la conservación se han usado depósitos de
PVC de 100 I de capacidad. Los dispositivos de aireación son los mismos que se han usado con anterioridad en el estudio de la fermentación aeróbica de aceitunas negras maduras (13) y el caudal de aire que se inyecta es de $0,3 \mathrm{l} / \mathrm{h}$.lc. (litros por hora y por litro de capacidad) durante 8 horas al día.

Las determinaciones físico-químicas de control se realizan según los métodos habituales (14). En las siembras microbiológicas se utilizan distintos medios de cultivo para los bacilos Gramnegativos, levaduras y bacterias lácticas, empleando para los resultados cuantitativos el cálculo del recuento estandar en placa (15).

Las aceitunas se colocan en una salmuera cuyas características se recogen en el Esquema 1, en el que también se especifican las particularidades de los diferentes procesos de conservación que se ensayan. La concentración de $\mathrm{NaCl}$ se mantiene en los valores prefijados por sucesivas adiciones de sal.

\section{Esquema 1}

Características de las diversas experiencias de conservación.

Concentración inicial $(\%, P / V)$

Tipo de

proceso

Inoculación $\mathrm{NaCl}$ Acido acético

Anaeróbico

Sí

No

6

0,3

Anaeróbico

Sí

Aeróbico

Aeróbico

$$
\text { No }
$$

6

0,3

Medio ácido

$$
\text { No }
$$

Sí
No
No
No

6

0,3

Medio ácido

6
6
3

0,3

Al cabo de 12 meses, se procede a la oxidación de los frutos. Las condiciones de los tratamientos alcalinos fueron: primera lejía $1,5 \%$ de $\mathrm{NaOH}$, segunda y tercera, 1,0\%, penetrando respectivamente, la piel, un milímetro y hasta el hueso. Después de cada una de ellas, las aceitunas se colocan en agua y se airean hasta el día siguiente, corrigiéndose regularmente el $\mathrm{pH}$ del medio para que el mismo no supere las 8,0 unidades. Al cuarto día, el color desarrollado se fija, sumergiendo los frutos en una solución al $0,1 \%$ de gluconato ferroso durante 24 horas, periodo a lo largo del cual se mantiene la aireación.

El envasado se lleva a cabo en botes de hojalata de $1 / 2$ kilo, con unos $250 \mathrm{~g}$ de fruto, empleando como líquido de gobierno una salmuera nueva con el $2 \%$ (P/V) de $\mathrm{NaCl}$ a la que se adiciona gluconato ferroso en una proporción del 0,03 ó 0,06\% (P/V). 
La esterilización se efectúa a $121^{\circ} \mathrm{C}$ durante 20 minutos en un autoclave Steriflow dotado de recirculación del agua de calentamiento o enfriamiento.

Los envases se abren a los dos meses, determinándose a las aceitunas el color superficial por reflectancia a $700 \mathrm{~nm}$ y la textura por compresión-cizallamiento (14).

\section{RESULTADOS Y DISCUSION}

3.1. Evolución de la flora microbiana de las salmueras durante la conservación

Los resultados del análisis cuantitativo de la población de microorganismos que se desarrolla en las salmueras de conservación se dan en las curvas de crecimiento en las Figuras 1, 2 y 3.

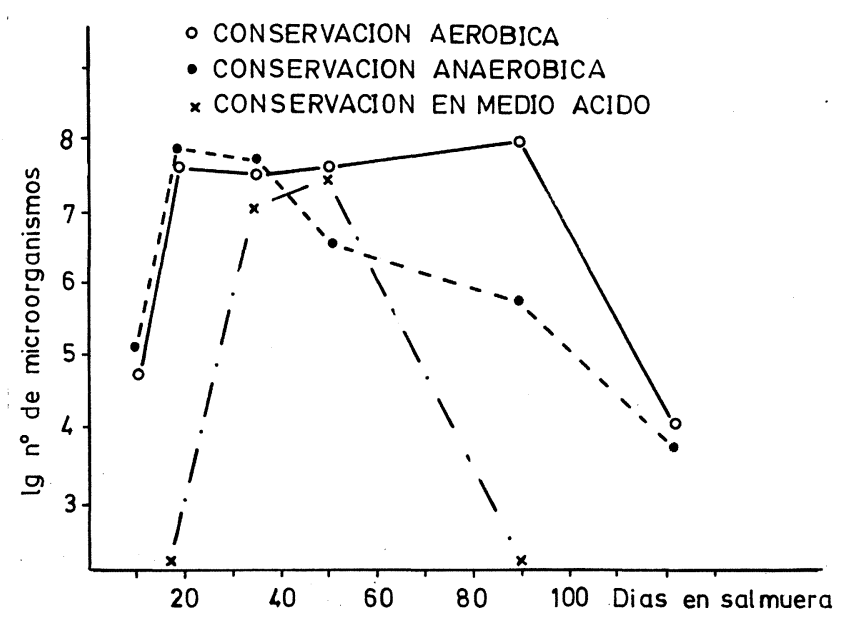

Figura 1

Evolución de la población de lactobacilos en las salmueras de conservación de los diferentes sistemas ensayados.

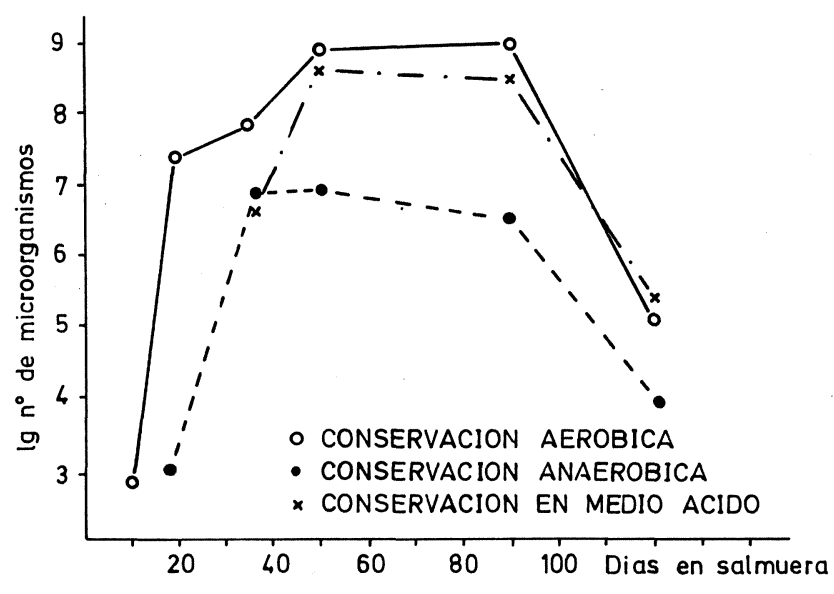

Figura 2

Evolución de la población de cocos lácticos en las salmueras de conservación de los diferentes sistemas ensayados.

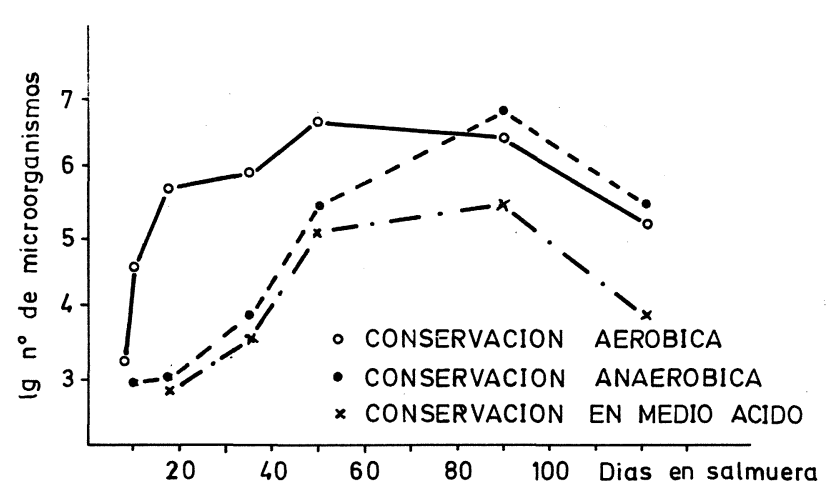

Figura 3

Evolución de la población de levaduras en las salmueras de conservación de los diferentes sistemas ensayados.

En las Figuras 1 y 2 se representa la evolución de la población láctica que crece en los tres sistemas estudiados. Es necesario destacar que el desarrollo ha sido más o menos abundante en los tres casos, no apreciándose diferencias entre los inoculados y los que no lo han sido. Esta población está compuesta por lactobacilos y por cocos lácticos, que han crecido espontáneamente en todos los fermentadores en forma variable.

En el proceso anaeróbico y aeróbico los lactobacilos inician su desarrollo alrededor de los 7-8 días. En el primero de ellos, alcanzan el máximo entre los 20-30 días, momento a partir del cual la población decrece gradualmente. En el aeróbico, se aprecia una presencia semejante en las mismas fechas anteriores, si bien se continúa observando una tendencia a aumentar de manera lenta, por lo que dichos microorganismos presentan sus cifras de recuento más altas hacia los 90 días, iniciando inmediatamente un rápido descenso. En ambos casos la actividad de estos gérmenes se prolonga hasta el final de la conservación aunque a unos niveles que van siendo inferiores a medida que transcurre el tiempo.

Los cocos lácticos en el sistema aerobio comienzan su crecimiento al mismo tiempo que los lactobacilos, aunque con cifras de recuento bastante inferiores, mientras que en el anaerobio lo hacen en fechas posteriores. Este mismo desplazamiento se observa también en los máximos respectivos, que en el caso aerobio es el más elevado de toda la población láctica. Dicho desarrollo abundante se mantiene también hasta los 90 días, momento en el que inician se decrecimiento, si bien permanecen, asimismo, hasta el final del periodo en salmuera.

En la conservación en medio ácido es en la que se observa desde las primeras fechas una población 
menor de lactobacilos y el máximo menos elevado, siendo su período de permanencia más corto, ya que estos gérmenes llegan, incluso, a desaparecer, a los 70-80 días.

Los cocos lácticos inician su crecimiento, igualmente, en un período más tardío que en los otros sistemas de conservación, si bien presentan cifras de recuento superiores a los lactobacilos en su máximo crecimiento $y$, por otro lado, permanecen en la salmuera durante el resto del periodo de conservación.

En los tres casos, la población de cocos lácticos que se han desarrollado espontáneamente está compuesta por bacterias cocáceas y tienen como características genéricas la agrupación en tetradas en medio líquido Lemco, prueba de la catalasa negativa, tinción Gram-positiva y no producen $\mathrm{CO}_{2}$ en su metabolismo. Por estas pruebas se puede deducir que dichos microorganismos pertenecen al género Pediococcus.

En la Figura 3 se representa la evolución de la población de levaduras que se ha desarrollado en los tres sistemas de conservación estudiados. Estos gérmenes crecen desde las primeras fechas en todos ellos, teniendo un desarrollo variable según las características de los mismos.

En la conservación anaerobia esta población se inicia con cifras de recuento muy bajas, subiendo gradualmente hasta llegar al máximo, que se alcanza alrededor de los 90 días. A partir del mismo la población decrece ligeramente pero permaneciendo hasta las últimas fechas.

En la conservación con inyección de aire este crecimiento es más elevado en los primeros días, alcanza su máximo en fechas anteriores y persiste durante más tiempo. Esta población superior de levaduras que se observa en medio aerobio es consecuencia probablemente, de la presencia del aire, ya que cuando hay un aporte de éste se incrementa en gran medida la masa celular y se tiene una mayor disponibilidad de materia fermentable, debido a que la recirculación del medio facilita su extracción de la pulpa de los frutos.

En el medio ácido, a causa de la elevada concentración de acético se aprecia una tendencia diferente: estos microorganismos aparecen más tarde que en los casos anteriores y con una población sensiblemente inferior, siendo su máximo poco elevado en relación con los demás métodos de conservación.

Respecto a otros gérmenes que se suelen desarrollar en las salmueras de fermentación, se puede indicar que los bacilos Gram-negativos prácticamente no han crecido, ya que sólo se han encontrado escasas colonias, en fechas aisladas. Asimismo, tampoco se ha observado la presencia de bacilos del género Bacillus.
3.2. Evolución de las características físicoquímicas de frutos y salmueras durante la conservación

Para cada uno de los sitemas de conservación ensayados la evolución de los distintos parámetros ha sido similar en los dos replicados, no apreciándose tampoco diferencias debido a la inoculación o no y a las diferentes concentraciones de sal empleadas en el medio ácido. Por ello, los comentarios se hacen de forma general para cada procedimiento estudiado.

\section{Azúcares reductores}

De la observación de la Figura 4 se deduce que el descenso más rápido en la concentración de azúcares en la pulpa de los frutos se produce cuando se inyecta aire en la salmuera, debido a que la recirculación que éste provoca en el líquido favorece la difusión. El más lento es el proceso con adición de acético en una proporción del 1,5\% (P/V), a causa de que el efecto osmótico en este caso, es menor, como consecuencia de la presencia del propio ácido y de la acumulación de sustancias orgánicas, fundamentalmente azúcares (Figura 5), que son metabolizados con cierta lentitud al haber en estos fermentadores un menor desarrollo de microorganismos.

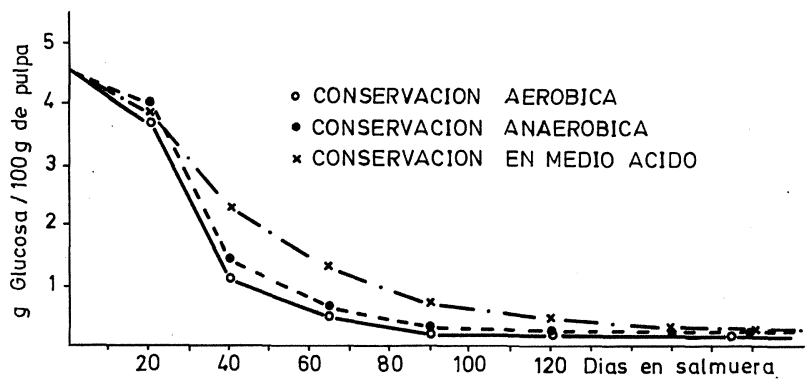

Figura 4

Evolución de los azúcares en la pulpa de los frutos de los diferentes sistemas de conservación ensayados.

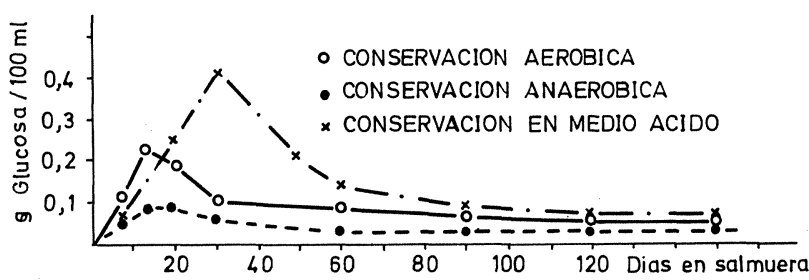

Figura 5

Evolución de los azúcares disueltos en las salmueras de conservación de los diferentes sistemas ensayados. 
Por ello, en el medio ácido los azúcares no desaparecen de la pulpa hasta pasados unos 150 días de la colocación en salmuera, mientras que en la fermentación aeróbica esto ocurre a partir de los tres meses y en la anaeróbica en una fecha intermedia.

Por lo que respecta a la salmuera, se ha encontrado una acumulación de estas sustancias al principio de la conservación, en especial en el medio ácido y aerobio. Una vez transcurridos los dos primeros meses, las diferencias han ido desapareciendo y el comportamiento de los tres sistemas se ha hecho cada vez más semejante.

La cantidad residual que se encuentra al final del proceso, tanto en los frutos $(0,4-0,5 \%, P / V)$ como en la salmuera $(0,04-0,08 \%, P / V)$, no es real, sino que es una interferencia en el método de análisis causada por el carácter reductor de algunas de las sustancias presentes, frente al licor de Fehling, fundamentalmente de tipo polifenólico.

\section{pH y acidez libre de las salmueras}

Como se puede observar en la Figura 6, en todos los casos se produce un aumento de los valores de $\mathrm{pH}$ durante los primeros días.

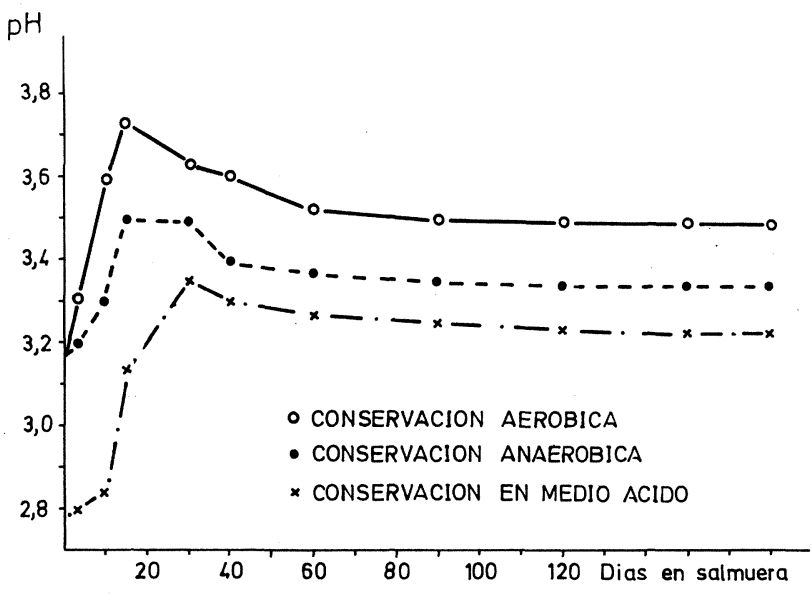

Figura 6

Evolución del $\mathrm{pH}$ en las salmueras de conservación de los diferentes sistemas ensayados.

Al comparar las evoluciones de los fermentadores aeróbicos y anaeróbicos se aprecia que, aunque se parte del mismo valor inicial, cuando existe inyección de aire se tiene un máximo más elevado, debido a que la recirculación del líquido origina un paso más rápido de los compuestos hidrosolubles a la salmuera (16). A partir de los 15 días se inicia un progresivo descenso hacia los valores de equilibrio a causa del desarrollo de las bacterias lácticas, con la consiguiente producción de ácido.

De forma similar evoluciona el proceso con adición de ácido acético, la curva correspondiente se mantiene en valores inferiores por efecto de la mayor concentración de ácido. En este caso, además, la variación posterior es muy suave y lenta ya que las bacterias lácticas se desarrollan más tardíamente y en menor número que en el resto de los procedimientos que se ensayan.

En relación con la acidez libre (Figura 7), en la conservación en medio ácido se tiene un descenso muy acusado de ella al principio, a causa de la penetración del mismo en la pulpa, hasta que se alcanza el equilibrio. Luego, se incrementa de forma paralela a las demás. En los otros sistemas ensayados apenas es perceptible ningún mínimo, observándose una subida paulatina, para alcanzar unos niveles finales muy parecidos, pero claramente inferiores al primero, manteniéndose las diferencias que se establecieron con la adición inicial.

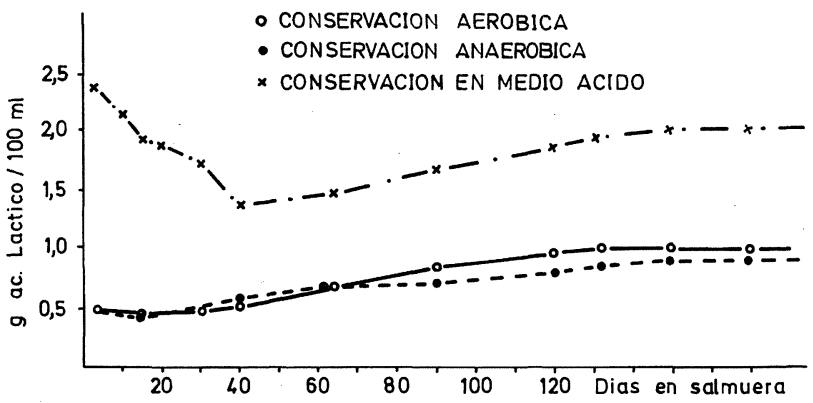

Figura 7

Evolución de la acidez libre de las salmueras de conservación de los diferentes sistemas ensayados.

\section{Anhidrido carbónico y oxigeno disuelto en las sal- mueras}

En la Figura 8 se observa que los valores más elevados de $\mathrm{CO}_{2}$ disuelto se dan cuando no se pasa aire, apreciándose un comportamiento semejante en los anaeróbicos y en medio ácido. La concentración de ambos casos aumenta paulatinamente hasta que, a partir de los 40 días, se estabilizan para, después, ir disminuyendo muy ligeramente.

Cuando se mantienen unas condiciones aeróbicas, la proporción es siempre pequeña, apreciándose las concentraciones más altas hasta los 7-9 días de la colocación en salmuera, para disminuir seguidamente, por efecto de la purga a que la aireación da lugar, y estabilizarse a partir de los 30 días. 


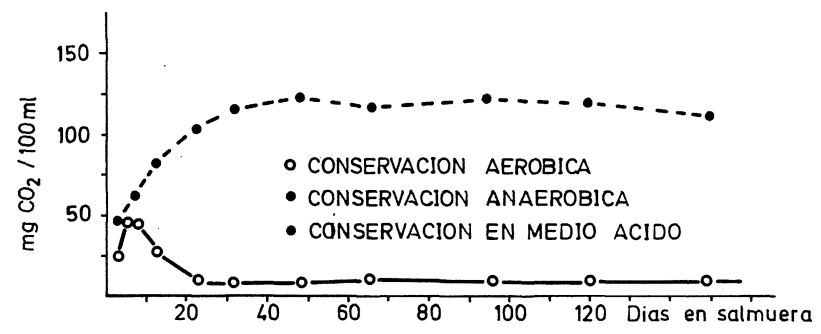

Figura 8

Evolución del anhídrido carbónico disuelto en las salmueras de conservación de los diferentes sistemas ensayados.

Respecto al oxígeno disuelto, las concentraciones menores se tienen, según puede verse en la Figura 9 , cuando se inyecta aire, debido a que el $\mathrm{O}_{2}$ que se aporta es consumido con mayor facilidad por los microorganismos de tipo facultativo que predominan en estas condiciones. En cualquier caso la forma de las curvas es similar y muestra una disminución importante que se inicia al tercer o cuarto día y continúa a lo largo de los treinta primeros, posiblemente por efecto de la actividad respiratoria de los frutos, el aumento de la población de microorganismos con cuyas curvas de crecimiento tanto de bacterias lácticas como de levaduras puede fácilmente correlacionarse $e$, incluso, quizás, a causa de la influencia sobre la solubilidad de este gas de la propia salmuera.

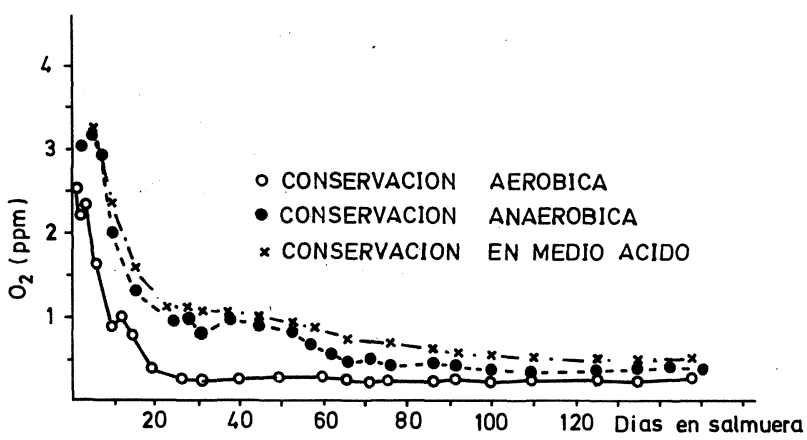

Figura 9

Evolución del oxígeno disuelto en las salmueras de conservación de los diferentes sistemas ensayados.

Al final, sin embargo, aunque siguen observándose las tendencias mencionadas, las diferencias son muy escasas $y$, en general, el oxígeno disuelto es inferior a $0,5 \mathrm{ppm}$.

\section{Textura de los frutos}

En la Tabla I se recogen los valores medios de las medidas por compresión-cizallamiento realizadas al cabo de un año en salmuera.
Tabla I

Textura por compresión-cizallamiento $\left(\mathrm{kg} / \mathrm{cm}^{2} \cdot 100\right.$ $\mathrm{g}$ de fruto deshuesado) de los frutos después de un año en salmuera, según los diferentes tratamientos de conservación ensayados.

Textura según sistema de conservación*

Anaeróbico Aeróbico Medio ácido

$\begin{array}{llll}\text { Con inoculación } & 19,4 & 18,3 & 18,6 \\ \text { Sin inoculación } & 19,7 & 19,1 & 19,1\end{array}$

NOTA: *Valores medios de dos replicados con diez determinaciones cada uno.

Desviación típica ponderada de las medias: 0,44 .

Del análisis de varianza realizado a partir de los resultados individuales se pone de manifiesto que con respecto a este atributo, no hay diferencias significativas entre los distintos sistemas de conservación ensayados ni entre los casos de inoculación o no con un cultivo puro de lactobacilos.

Además, teniendo en cuenta que el valor inicial de textura del fruto fresco era de $20,4\left(\mathrm{~kg} / \mathrm{cm}^{2} \cdot 100\right.$ $\mathrm{g}$ de fruto deshuesado), se puede decir que durante este período apenas ha habido degradación de la consistencia. En todos los casos se ha conseguido un producto totalmente apto para la oxidación que no presentaba arrugado superficial alguno.

Sin embargo, hay que tener en cuenta que, a nivel industrial, en los procesos en los que no se purga el $\mathrm{CO}_{2}$, se suele producir una mayor acumulación de dicho gas a causa del diseño de los fermentadores y de que la proporción fruto/salmuera (2:1) es superior a la que usualmente se emplean en el laboratorio, lo que, sin duda, llevaría a la formación de arrugas superficiales al sacar las aceitunas de los depósitos. Por ello, cuando se trate de frutos para elaborar como tipo negras, es recomendable el empleo del sistema aeróbico.

\subsection{Características de los frutos después de} los tratamientos de oxidación

En la Tabla II se recogen los valores medios de los porcentajes de reflectancia de los frutos de cada sistema de conservación ensayados, una vez preparados como tipo negras. De un primer estudio, se desprende que, a pesar de la conocida dificultad de las aceitunas de la variedad Gordal para desarrollar un color negro intenso, se alcanzan en estas experiencias una buena coloración final. 
Tabla II

Color de los frutos oxidados (\% de reflectancia a $700 \mathrm{~nm}$ ). Valores medios según los tratamientos de conservación y los porcentajes de gluconato ferroso adicionado al líquido de gobierno.

Color según sistema de conservación ${ }^{*}$

Gluconato en

el líquido de gobierno (\%)

Anaeróbico Aeróbico

Medio ácido

$\begin{array}{llll}0,03 & 7,1 & 7,9 & 6,9 \\ 0,06 & 6,7 & 7,1 & 6,7\end{array}$

NOTA: *Valores medios de dos replicados con diez determinaciones cada uno.

Desviación típica ponderada de las medias: 0,62

Del análisis de varianza realizado a partir de los resultados individuales se concluye que no se encuentran diferencias significativas entre los distintos sistemas de conservación ni, incluso, entre los dos niveles de sal de hierro empleados en el líquido de gobierno de envasado, aunque, en este caso, sí se observa una tendencia a obtenerse menores valores de reflectancia cuando se emplea la mayor proporción de gluconato ferroso $(0,06 \%)$.

Las medias de las medidas de textura por compresión-cizallamiento para los distintos medios de conservación ensayados se muestran en la Tabla III. Es de destacar que estos valores vienen a ser aproximadamente la mitad de los recogidos en la Tabla I. Es decir, durante el preceso de ennegrecimiento y esterilización se ha producido una dismunición en la consistencia de las aceitunas de, aproximadamente, un $50 \%$.

\section{Tabla III}

Textura por compresión-cizallamiento $\left(\mathrm{kg} / \mathrm{cm}^{2} \cdot 100\right.$ $\mathrm{g}$ de fruto deshuesado) de los frutos oxidados. Valores medios de los replicados obtenidos según los tratamientos de conservación y porcentaje de gluconato ferroso en el líquido de gobierno.

Textura según sistema de conservación*

Gluconato en

el líquido de gobierno (\%)

$\begin{array}{llll}0,03 & 9,4 & 8,8 & 9,5 \\ 0,06 & 9,2 & 9,0 & 9,3\end{array}$

NOTA: "Valores medios de los replicados con diez determinaciones cada uno.

Desviación típica ponderada de las medias: 0,48

Del estudio estadístico de los datos individuales se desprende que, al igual que ocurre cuando este análisis se realiza antes del proceso de ennegrecimiento, no hay un efecto significativo sobre la textura final atribuible a los tratamientos de conservación ni, como era de esperar, al empleo de las dos concentraciones de sal de hierro utilizadas en el líquido de gobierno del envasado.

\section{CONCLUSIONES}

De todo lo expuesto puede concluirse que los diferentes métodos, que se han ensayado, para mantener las aceitunas de la variedad Gordal hasta el momento de su preparación, dan origen a un producto final de un color y textura muy aceptable y sin que existan diferencias en estos atributos de calidad por efecto de los distintos tratamientos de conservación. No obstante, sin embargo, a nivel industrial, es recomendable la utilización del sistema aeróbico, que evita la acumulación de anhídrido carbónico hasta concentraciones que puedan producir arrugado.

La flora microbiana que crece está constituida, fundamentalmente, por bacterias lácticas y levaduras, que presentan un desarrollo variable, según el método de conservación. Las bacterias lácticas se desarrollan en los tres métodos con independencia de que exista o no inoculación. Esta población está compuesta por bacilos pertenecientes al género Lactobacillus y por bacterias cocáceas del género Pediococcus que crecen espontáneamente. Estas últimas muestran un mayor desarrollo y el máximo más elevado que los lactobacilos en la conservación aeróbica y medio acidificado. Los lactobacilos, por el contrario, tienen un crecimiento superior a los cocos lácticos únicamente durante un cierto período en el tratamiento anaeróbico y tienen la población más baja en la conservación en medio ácido, en la que llegan a desaparecer al cabo de unos tres meses.

Las levaduras, asimismo, se desarrollan en los tres sistemas estudiados, alcanzando un máximo desarrollo dependiendo del método utilizado. Estos microorganismos alcanzan en el sistema aeróbico su mayor población desde los primeros días y también al máximo más elevado; siendo, por el contrario, en el medio ácido donde su presencia es menor y da el máximo más bajo.

Las condiciones físico-químicas que se alcanzan rápidamente, por efecto del desarrollo de las bacterias lácticas gracias a las concentraciones, iniciales de 
$\mathrm{NaCl}$ inferiores al 7\% (P/V), aseguran la conservación del producto sin riesgo de que se produzcan alteraciones que afecten a la textura. Al mismo tiempo, tampoco han mostrado efectos apreciables sobre el color de los envasados.

En definitiva, se propone la utilización del método aeróbico, utilizando niveles iniciales bajos de sal, corrección del $\mathrm{pH}$ con acético y, si existiera la duda sobre la presencia de bacterias lácticas en el ambiente o en los frutos, la utilización de inóculos de Lactobacillus plantarum, para asegurar durante la conservación la predominancia de un proceso fermentativo de tipo láctico. Debido a la gran facilidad que presenta esta variedad para el mismo, cualquier cultivo de los que se ofrecen en el mercado puede ser válido.

\section{AGRADECIMIENTO}

A la CICYT por la financiación del Proyecto Ali 88-01521-002-01, dentro del cual se ha efectuado esta investigación.

A doña Mercedes Bodineau Bada por su ayuda técnica en el laboratorio.

\section{BIBLIOGRAFIA}

1. Garrido Fernández, A., Durán Quintana, M. C., y González Cancho F.-"Aceitunas negras al natural en salmuera. VIII. Estudio de la influencia de diferentes tratamientos y formas de fermentación sobre la alteración denominada "alambrado"".-Grasas y Aceites 30 (1979) 301-307.

2. Garrido Fernández, A., Durán Quintana, M.C., Garcia Garcia, P. y Brenes Balbuena, M.-"Aceitunas de color cambiante. Estudio comparativo de algunos métodos de conservación".- II Congreso Mundial de Tecnología de Alimentos. Barcelona, 1987.

3. Rodríguez de la Borbolla y Alcalá, J. M., González Pellissó, F. y González Cancho, F.-"Aceitunas verdes y de color cambiante en salmuera. I."-Grasas y Aceites 22 (1971) 455-460.

4. Garrido Fernández, A., Durán Quintana, M.C. y Garcia Garcia, P.-"Estudio de diferentes formas de conservación de aceitunas de color cambiante de la variedad Manzanilla".-Grasas y Aceites 37 (1987) 1-7.
5. Brenes Balbuena, M., Garcia García, P., Durán Quintana, M.C y Garrido Fernández, A.-"Estudio comparativo de sistemas de conservación de aceitunas tipo negras".-Grasas y Aceites 37 (1986) 123-128.

6. Garrido Fernández. A., Garcia Garcia, P. y Sánchez Roldán F.-"Nuevo proceso aeróbico de fermentación de aceitunas negras al natural. Optimización de la columna de aireación".-Aliment. Equipos Tecnol. Mayo-Junio (1985) 73-81.

7. Brenes Balbuena, M., García García, P. y Garrido Fernández, A.-"Estudio comparativo de sistemas de conservación de aceitunas tipo negras. II. Efecto sobre las características del producto final".-Grasas y Aceites 37 (1986) 301-306.

8. Vaughn, R. H.-"Progress Report on Saltless Storage".-48th Annual Technical Report of the California Olive Association, 1969.

9. Vaughn, R. H., Stevenson, K.E., Meyer, M.T. and Patel I.G.-"Progress Report on the Year's Research with Olives".-49 th Annual Technical Report of the California Olive Association, 1970.

10. Ralls, J. W.-"Alternative Storage Systems".-46th Annual Technical Report of the California Olive Association, 1967.

11. Ralls, J. W.-"Alternative Storage Systems".-47th Annual Technical Report of the California Olive Association, 1968.

12. Ralls, J. W.-"The Use Activated Carbon to Renovate Brines".-48th Annual Technical Report of the California Olive Association, 1969.

13. Garcia Garcia, P., Durán Quintana, M.C. y Garrido Fernández, A.-"Fermentación aeróbica de aceitunas maduras en salmuera".-Grasas y Aceites 36 (1985) 14-20.

14. Fernández Diez, M. J. et al.-"Biotecnologia de la Aceituna de Mesa".- Instituto de la Grasa y sus Derivados (C.S.I.C.). Sevilla 1985.

15. ICMS.-"International Comission on Microbiological Specifications for Foods".-Microorganismos de los Alimentos. Vol. 1. Técnicas de Análisis Microbiológico. Editorial Acribia. Zaragoza, 1983.

16. Durán Quintana, M.C., Garcia Garcia, P. y Garrido Fernández, A.-"Fermentación en medio aeróbico de aceitunas maduras en salmuera con inyección alternante de aire. Estudio de la influencia de la adición de cloruro cálcico sobre la textura".- Grasas y Aceites 37 (1986) 242-249.

(Recibido: Junio 1990) 